\title{
Geriatrie
}

\begin{tabular}{l|l} 
Prof. Dr. med. Antonius Schneider & $\begin{array}{l}\text { 47-Geriatrisches Basisassessment } \\
51 \text { - Visite im Pflegeheim } \\
\text { Facharzt für Allgemeinmedizin, Institut für Allgemeinmedizin } \\
\text { Technische Universität München/Klinikum rechts der Isar, München } \\
\text {-therapie }\end{array}$ \\
\hline
\end{tabular}

Immer mehr ältere Patienten sind zu versorgen

\section{Hausarzt im Zeichen der „Alterszwiebel“}

- Die meisten von Ihnen hatten in den Schuljahren in den gesellschaftspolitischen Fächern sicherlich noch die Alterspyramide gelernt - mittlerweile hat sich diese eher in eine „Alterszwiebel“ verändert. Dies wurde uns damals schon in der Gymnasialzeit prophezeit - und seltsamerweise hat die Politik bisher immer noch keine wesentlichen Anstrengungen unternommen, um diese Entwicklung aufzuhalten.

In der Praxis bringt diese Entwicklung auf jeden Fall Arbeit zuhauf. Bekanntermaßen nimmt im steigenden Lebensalter die Multimorbidität zu. Gemäß dem Deutschen Alterssurvey (DEAS) leidet mehr als die Hälfte der Menschen ab 55 Jahren an mindestens zwei chronischen Erkrankungen, ab 70 Jahren leiden $24 \%$ an mindestens fünf chronischen Erkrankungen [1]. Eine hausärztliche Studie in Kanada

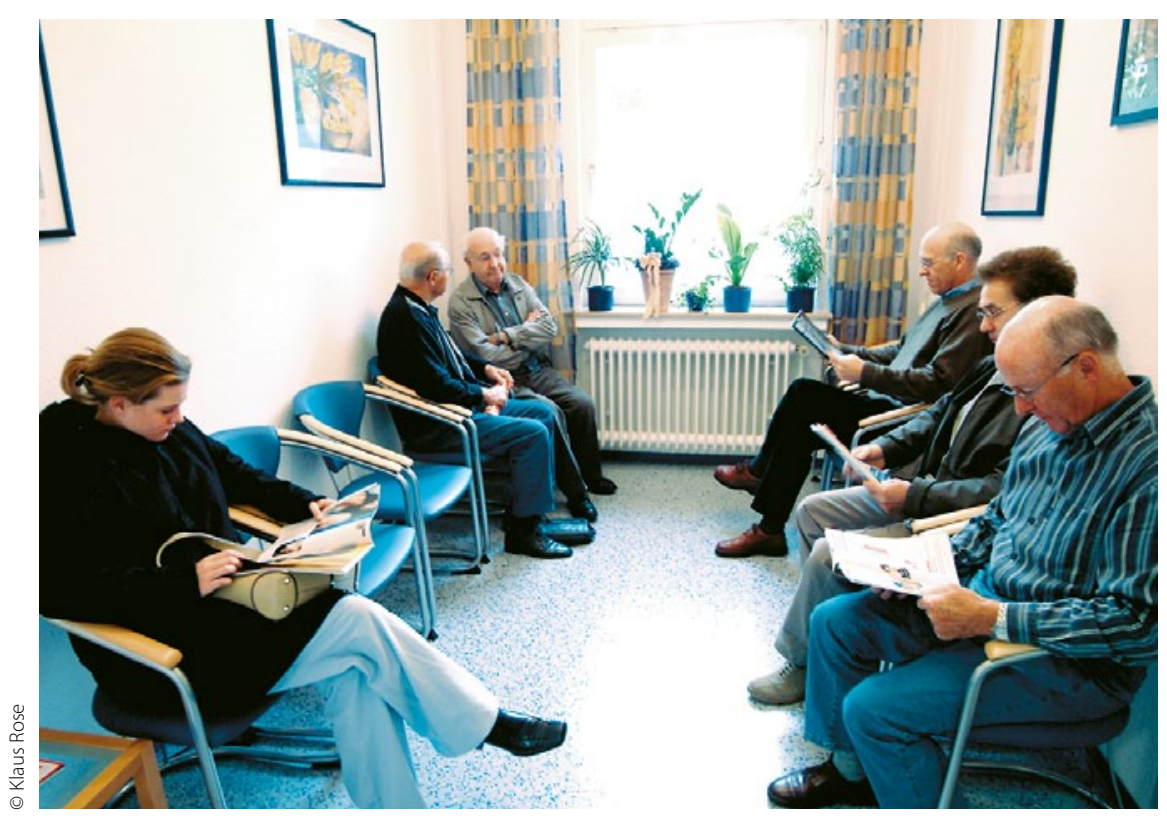

hat gezeigt, dass sich das auch in einer entsprechenden Morbiditätsverdichtung in der Hausarztpraxis zeigt [2].

Entsprechend die Situation im Altenheim: Auch hier müssen die Patienten im Hinblick auf zahlreiche Erkrankungen betreut werden.

Oft muss jedoch sorgsam gemeinsam mit dem Patienten abgewogen werden, welches Maß an Medizin im hohen Alter noch sinnvoll ist und zum Lebenskontext und den Wünschen der Betroffenen passt. Viele Dinge hierzu sind noch wenig erforscht bzw. sind nur vereinzelt und verstreut in Lehrbüchern zu finden.

Vor dem Hintergrund der oben skizzierten Entwicklungen kommen auf uns Hausärztinnen und Hausärzte viele komplexe Aufgaben zu. Die folgenden Artikel "Geriatrisches Basisassessment ${ }_{\text {, }}$,Altenheimvisite" und "Wundversorgung" sollen Ihnen ganz praktische und hilfreiche Tipps hierfür bieten.

Übrigens: Komplexität in der Allgemeinmedizin bildet eine Herausforderung und Chance zugleich, denn hier können wir Hausärzte uns bewähren. Dies möchten wir im nächsten Jahr auf dem Kongress der Deutschen Gesellschaft für Allgemeinmedizin (DEGAM; www.degam.de) in München näher beleuchten. Reservieren Sie sich den Termin vom 12.-14.9.2013!

\section{Literatur unter mmw.de}

Jüngere Patienten sind in unseren Wartezimmern heute meist in der Minderheit. 